\title{
Bactérias multirresistentes e seus impactos na saúde pública: Uma responsabilidade social
}

\author{
Multirresistant bacteria and their impacts on public health: A social responsability \\ Bacterias multirresistentes y sus impactos en la salud pública: Una responsabilidade social
}

Recebido: 19/05/2021 | Revisado: 24/05/2021 | Aceito: 25/05/2021 | Publicado: 10/06/2021

Juliana Jeanne Vieira de Carvalho

ORCID: https://orcid.org/0000-0003-4591-2639 Centro Universitário São Lucas, Brasil E-mail: julianajvcarvalho@gmail.com

Felipe Gomes Boaventura

ORCID: https://orcid.org/0000-0002-0654-7336 Centro Universitário São Lucas, Brasil

E-mail: felipegoboaventura@gmail.com

Anitha de Cássia Ribeiro da Silva

ORCID: https://orcid.org/0000-0003-2079-9457 Centro Universitário São Lucas, Brasil

E-mail: anithadecassia@gmail.com

Rhuana Lima Ximenes

ORCID: https://orcid.org/0000-0001-9201-4685 Centro Universitário São Lucas, Brasil E-mail: julianajvcarvalho@gmail.com

Luana Kamila Castilho Rodrigues ORCID: https://orcid.org/0000-0002-2634-7251 Centro Universitário São Lucas, Brasil E-mail: luanakamila.castilho@gmail.com

Diego Antônio de Almeida Nunes

ORCID: https://orcid.org/0000-0003-0406-6747 Centro Universitário São Lucas, Brasil E-mail: diegoalmeidamed@hotmail.com

Viviane Krominski Graça de Souza

ORCID: https://orcid.org/0000-0001-7773-932X

Universidade Estadual de Maringá, Brasil E-mail: krominskiviviane@gmail.com

\begin{abstract}
Resumo
Introdução: Seres humanos convivem de modo comensal com inúmeras bactérias, porém espécies patogênicas assolaram a humanidade por milênios até o advento dos primeiros antibióticos. Entretanto, o uso indiscriminado de antibióticos, tanto em hospitais quanto na agropecuária, tem gerado altas taxas de resistência bacteriana e se tornado um problema com disrupção eminente. O presente estudo visa analisar a etiologia multifatorial dos mecanismos de multirresistência bacteriana, a prevalência das principais bactérias envolvidas nesse processo e seu impacto na saúde pública. Metodologia: Trata-se uma revisão integrativa de literatura acerca dos processos e consequências da resistência bacteriana. O critério de inclusão foi a compatibilidade com o tema e a relevância. Resultados: Analisados 46 artigos dos quais metade são artigos originais. Dentre estes, 6 artigos realizaram levantamento da prevalência de bactérias farmacorresistentes em ambientes nosocomiais, com amostragem de 646 pacientes nos quais foram isolados Klebsiella pneumoniae em 27,11\%, Pseudomonas aeruginosa em 19\%, seguida por Escherichia coli com 16\%, e Staphylococcus aureus com 4,75\%. Discussão: Com 25 a $50 \%$ das administrações antibióticas em hospitais consideradas irregulares, seu uso indiscriminado e a lenta formulação de novas opções terapêuticas, entre outros, contribuiu com o desenvolvimento de cepas bacterianas multirresistentes durante a era dos antimicrobianos. Os principais mecanismos de farmacorresistência incluem modificação antibiótica; impedimento da ação do antibiótico em seu alvo; alteração do sítio primário de ligação; e produção de alvo alternativo para burlar o efeito do fármaco. Considerações Finais: A multirresistência bacteriana aumenta a morbimortalidade, tempo de internação e gastos com insumos e equipe especializada. Estabeleceu-se como um problema que tende a agravar com o tempo, portanto, estudos abrangentes focados na prevalência bacteriana são necessários para traçar estratégias de saúde pública visando seu controle.
\end{abstract}

Palavras-chave: Farmacorresistência bacteriana; Infecções bacterianas; Saúde pública. 


\begin{abstract}
Introduction: Human beings coexist with numerous bacteria, but pathogenic species have plagued mankind for millennia until the advent of the first antibiotics. However, the indiscriminate use of antibiotics, both in hospitals and in agriculture, has generated high rates of bacterial resistance and has become a problem with imminent disruption. The present study aims to analyze the multifactorial etiology of bacterial multiresistance mechanisms, the prevalence of the main bacteria involved in this process and its impact on public health. Methodology: This is an integrative literature review about the processes and consequences of bacterial resistance. The inclusion criterion was compatibility with the theme and relevance. Results: 46 articles were analyzed, half of which are original articles. Among these, 6 articles carried out a survey of the prevalence of pharmacoresistant bacteria in nosocomial environments, with a sample of 646 patients in which Klebsiella pneumoniae was isolated in $27.11 \%$, Pseudomonas aeruginosa in 19\%, followed by Escherichia coli with 16\%, and Staphylococcus aureus with 4.75\%. Discussion: With 25 to $50 \%$ of antibiotic administrations in hospitals considered irregular, their indiscriminate use and the slow formulation of new therapeutic options, among others, contributed to the development of multidrug-resistant bacterial strains during the antimicrobial era. The main pharmacoresistance mechanisms include antibiotic modification; preventing the action of the antibiotic on its target; alteration of the primary binding site; and producing an alternative target to circumvent the drug's effect. Final Considerations: Bacterial multidrug resistance increases morbidity and mortality, length of hospital stay and expenses with supplies and specialized staff. It was established as a problem that tends to worsen over time, therefore, comprehensive studies focused on bacterial prevalence are necessary to outline public health strategies aimed at its control.
\end{abstract}

Keywords: Bacterial drug resistance; Bacterial infections; Public health.

\title{
Resumen
}

Introducción: Los seres humanos coexisten con numerosas bacterias, pero las especies patógenas han plagado a la humanidad durante milenios hasta la llegada de los primeros antibióticos. Sin embargo, el uso indiscriminado de antibióticos, tanto en hospitales como en agricultura, ha generado altas tasas de resistencia bacteriana y se ha convertido en un problema de disrupción inminente. Este estudio tiene como objetivo analizar la etiología multifactorial de los mecanismos de multirresistencia bacteriana, la prevalencia de las principales bacterias involucradas en este proceso y su impacto en la salud pública. Metodología: Se trata de una revisión integradora de la literatura sobre los procesos y consecuencias de la resistencia bacteriana. El criterio de inclusión fue la compatibilidad con el tema y la relevancia. Resultados: se analizaron 46 artículos, la mitad de los cuales son originales. Entre estos, 6 artículos realizaron una encuesta de prevalencia de bacterias farmacorresistentes en ambientes nosocomiales, con una muestra de 646 pacientes en los que se aisló Klebsiella pneumoniae en un 27,11\%, Pseudomonas aeruginosa en un 19\%, seguida de Escherichia coli con un 16\%, y Staphylococcus aureus con 4,75\%. Discusión: Con 25 a $50 \%$ de las administraciones de antibióticos en hospitales consideradas irregulares, su uso indiscriminado y la lenta formulación de nuevas opciones terapéuticas, entre otras, contribuyeron al desarrollo de cepas bacterianas multirresistentes durante la era antimicrobiana. Los principales mecanismos de farmacorresistencia incluyen la modificación de antibióticos; prevenir la acción del antibiótico sobre su objetivo; alteración del sitio de unión primario; y producir un objetivo alternativo para eludir el efecto del fármaco. Consideraciones finales: La multirresistencia bacteriana aumenta la morbilidad y la mortalidad, la duración de la estancia hospitalaria y los gastos de suministros y personal especializado. Se estableció como un problema que tiende a agravarse con el tiempo, por lo que son necesarios estudios integrales enfocados en la prevalencia bacteriana para delinear estrategias de salud pública orientadas a su control.

Palabras-clave: Resistencia bacteriana a fármacos; Infecciones bacterianas; Salud pública.

\section{Introdução}

A pele é abrigo de diversos microrganismos provenientes do meio ambiente, mas que não produzem efeito patogênico. No entanto, quando há supressão da microbiota normal, pode haver crescimento de outros pequenos nichos bacterianos, culminando em infecções e, em algumas circunstâncias, representando grande perigo, especialmente para pacientes imunocomprometidos. A alteração desse equilíbrio pode decorrer do uso inadequado de determinado antimicrobiano, desencadeando seleção bacteriana (Mota et al., 2010).

Embora os antimicrobianos constituam uma das bases da medicina moderna, seu uso excessivo tem conduzido a altas taxas de adaptação bacteriana, propiciando resistência e tornando os fármacos ineficientes contra patógenos (Padiyara et al., 2018). Essa resistência tem se apresentado como um dos problemas mais relevantes no decorrer dos anos, em diversas partes do mundo, sendo importante analisar as consequências hospitalares e econômicas relacionadas ao manejo errôneo dos antibióticos, a exemplo do impacto na morbidade, tempo de internação e mortalidade dos pacientes (Del Fio et al., 2000). 
Kapadia et al. (2018) apontam que entre $25 \%$ a $50 \%$ das administrações antibióticas realizadas em hospitais, são consideradas irregulares ou desnecessárias. Entretanto, esses processos apresentam incidências diferentes que dependem da estrutura do serviço hospitalar, de fatores socioeconômicos, culturais e do conhecimento acerca dos antibióticos por profissionais da saúde e sociedade (Kapadia et al., 2018; Loureiro et al., 2016).

Outro ponto refere-se ao emprego de antibióticos fora da área médica, como os agentes de crescimento na agricultura, alimentação e criação animal: fatores que expuseram nos últimos setenta anos aos maiores índices de resistência bacteriana. Pesquisas apontam que atualmente ocorre uma grande versatilidade metabólica das bactérias para se desenvolverem em ambientes diversos, seja em águas poluídas, ou não; solos e diversos locais associados a reservatórios para a propagação de genes de resistência, bem como, com o uso abusivo de antimicrobianos em animais que são destinados para consumo humano. Nesse cenário, levantou-se uma média de mortalidade mundial por volta de 700.000 pessoas anualmente, sendo 23.000 delas, aproximadamente, somente nos Estados Unidos, com cerca de U\$20 milhões de dólares de despesas médicas adicionais. Somado a isso, os principais microrganismos associados às infecções aproveitam-se de um sistema imune debilitado para expressarem sua virulência, já que boa parte dos indivíduos acometidos são aqueles que passam longos períodos hospitalizados, em situação de vulnerabilidade da homeostase corporal (Padiyara, 2018; Hughes, 2014; Djouadi et al., 2017; Gay et al., 2018; Sabathier, 2019; Salam, 2020; Pons et al., 2020).

A era dos antibióticos está chegando ao fim, o que vem representando perigo não somente no ambiente hospitalar restrito, mas também para a sociedade, uma vez que algumas bactérias multirresistentes já transcendem os limites nosocomiais e tornaram-se muito prevalentes em infecções comunitárias. Por conseguinte, gera-se uma situação sanitária delicada e perigosa, visto que a produção de novos fármacos para combate dessas bactérias é lenta e indeterminada, levando a um impacto negativo na vida da população, animais e na qualidade de alimentos, além dos sistemas de produção, subsistência e desenvolvimento econômico de um país (Miquet, 2017).

Assim, objetiva-se realizar uma análise multifatorial dos mecanismos de multirresistência bacteriana, os principais agentes patogênicos multirresistentes, a quantidade e letalidade das infecções por elas causadas, a sobrecarga desse problema para os sistemas de saúde no Brasil e no mundo, além de identificar responsabilidades e viabilizar a discussão de perspectivas futuras, e reunir, assim, as informações já fornecidas.

\section{Metodologia}

O presente estudo trata-se uma revisão integrativa de literatura acerca dos processos e consequências da resistência bacteriana. O levantamento de artigos na literatura foi realizado entre dezembro de 2020 a maio de 2021, nos idiomas inglês, português e espanhol, lançando mão das bases de dados PUBMED/MEDLINE, Scientific Eletronic Library Online - SciELO, Google Scholar, Literatura Latino-Americana e do Caribe em Ciências da Saúde - LILACS e Rede de Revistas Científicas da América Latina e Caribe, Espanha e Portugal - REDALYC. Foram escolhidas essas bases de dados pois apresentam maior número de revistas indexadas e com maior renome mundial, incluindo a observância do aspecto multilinguístico e multiétnico, que tornam a análise do presente estudo mais abrangente.

As bases de dados permitiram um amplo estudo acerca do tema, conforme a realidade de diversos locais do mundo. Para seleção dos artigos foram utilizadas a combinação dos Descritores em Ciências da Saúde (DECS), como: "farmacorresistência bacteriana", "infecções bacterianas" e "saúde pública". Após o resultado inicial das buscas, mais filtros foram utilizados para melhor aprofundamento dos patógenpos mais encontrados, tais como "Staphylococcus aureus", "Pseudomonas aeruginosa", "Klebsiella pneumoniae", "Escherichia coli" em diversas combinações com "prevalência", "hospital", "UTI", "resistência" e "antibiótico", bem como seus respectivos linguísticos em inglês e espanhol. Os critérios de inclusão estabelecidos foram a relevância e compatibilidade acerca do tema, independente da data, enquanto os critérios de 
exclusão foram a incompatibilidade com o tema. Alguns dos artigos utilizados estão fora do escopo da área médica, no entanto, estabeleceram produções analíticas sobre bactérias sabidamente patogênicas no homem e suas farmacorresistências, por esse motivo, seus resultados relevantes foram incluídos neste trabalho.

\section{Resultados}

Foram analisados 46 artigos, dos quais metade são artigos originais ( 8 estudos retrospectivos, 3 estudos prospectivos, 2 estudos longitudinais, 8 estudos seccionais, 1 estudo qualitativo e 1 relato de caso). Destes, 6 estudos avaliaram a prevalência de bactérias multidroga-resistentes em ambientes nosocomiais, com um espaço amostral de 646 pacientes. K. pneumoniae foi responsável por $27,11 \%$ das infecções em todas as análises, entre pacientes pediátricos, adultos, de enfermaria e unidades de terapia intensiva. Em mais de $19 \%$ dos casos foi identificado P. aeruginosa, seguida por E. coli com 16\%, e S. aureus com 4,75\% (Mota et al, 2018; Basso et al, 2016; Bertão et al., 2018; Ribas, 2018; Debarba et al., 2018; Lima, 2018).

Antes uma bactéria comum e exclusivamente encontrada nas UTIs, Pseudomonas foi observada em culturas de pacientes à admissão hospitalar em dois terços dos casos, como revelou o estudo de Lima (2018). Dois trabalhos demonstram achados preocupantes: mutações dos genes integron integrase classe I em amostras de secreção e culturas assépticas identificaram cepas de $P$. aeruginosa, dentre as quais $23 \%$ são resistentes a carbapemenases e o relato de uma Klebsiella aerogenes produtora de metalo-beta-lactamase encontrada no Brasil, uma mutação já vista em outras enterobactérias causadoras de infecções sem resposta aos tratamentos atualmente disponíveis (Mota et al, 2018; Basso et al, 2016; Bertão et al., 2018; Ribas, 2018; Debarba et al., 2018; Lima, 2018).

Bactérias resistentes a antibióticos, como enterobactérias produtoras de beta-lactamases de espectro extendido (ESBL), foram isoladas também em ambientes extra-hospitalares, incluindo-se dois corpos d'água, uma fazenda e no solo de uma oficina automobilística (Djouadi et al., 2017; Gay, 2018; Salam, 2020; Sabathier, 2019).

\section{Discussões}

\subsection{Histórico}

Entre 1928 e 1929, Alexander Flemming descobriu a penicilina, iniciando a "época dos antibióticos". No decorrer das décadas, especialmente em 1940, sua produção cresceu em larga escala, marcando sua introdução no mercado, anunciando uma revolução no tratamento de infecções. Contudo, já em 1942, fora evidenciado o primeiro fenômeno de resistência natural, onde bactérias do grupo coli-tifóide não se encontravam mais sensíveis à penicilina, devido sua capacidade de produzir penicilinases, descritas por Abrahan e Chain, pela primeira vez (Bush, 1989; Souza et al., 2005; Clardy et al., 2009).

Após meados da década de 1960, somente quatro novas classes de antibióticos foram implementadas no mercado, onde a grande maioria era derivada de outros antibióticos, introduzidos entre os anos de 1930 e 1960. Este fenômeno potencializou um processo natural: o desenvolvimento de resistência bacteriana, que compromete a resposta clínica dos pacientes e aumenta os gastos com insumos e internações (Hughes, 2014; Souza et al., 2005; Clardy et al., 2009).

\subsection{O uso indiscriminado de antibióticos e suas implicações}

Os antimicrobianos abrangem moléculas de origem natural ou sintética que produzem os efeitos inibitórios ou letais para bactérias, fungos e protozoários. De forma geral, dividem-se em duas classes, conforme sua ação: os bactericidas e os bacteriostáticos. Os do primeiro grupo agem destruindo o microrganismo, representados por penicilina, vancomicina, aminoglicosídeos, fluoroquinolonas, daptomicina e metronidazol. Os do segundo grupo, por outro lado, são drogas bacteriostáticas, que para ação eficaz, o paciente deve estar com o sistema imune em plena atividade, sendo representadas pelos macrolídeos, clindamicina, tetraciclinas, sulfonamidas, linezolida e cloranfenicol (Mota et al., 2010). 
Esses fármacos estão entre os mais prescritos em hospitais no mundo para o tratamento de infecções. Todos os microrganismos que não possuem seu crescimento e multiplicação inibido pelas concentrações dos fármacos no sangue ou tecidos, bem como aqueles que não têm respostas clínicas durante o tratamento, são considerados resistentes, e multirresistentes quando possuem a capacidade de resistir aos efeitos de diversos antimicrobianos, sendo uma característica inerente às bactérias ou adquirida durante a infecção. Há ainda uma nova modalidade de resistência bacteriana, a panresistência, a qual é definida pela ausência de antimicrobianos que possam inibir o processo infeccioso. Esta última vem se tornando cotidiana dentro das unidades de terapia intensiva (Pons et al., 2020).

Deve-se considerar que nos últimos anos houve aumento de doenças infecciosas por bactérias resistentes aos antimicrobianos de amplo espectro, que juntamente ao processo de intercâmbio de pessoas e mercadorias entre países, fizeram com que esse problema ganhasse enfoque mundial. Assim, a Organização Mundial de Saúde (OMS) levantou os principais fatores que influenciam no desenvolvimento de resistência, dentre eles estão: prescrição em excesso; omissão da prescrição; doses e duração inapropriadas; seleção inadequada; gastos e riscos desnecessários (Vieira et al., 2017; Camou et al., 2017). Mota (2010) complementa: acesso facilitado ao consumo de antibióticos e automedicação; erro diagnóstico das infecções; ausência de comissão quanto ao uso de antimicrobianos no ambiente hospitalar; crença que o tratamento com antimicrobianos de amplo espectro seja mais eficaz, quando aplicado na terapêutica; desconhecimentos sobre administração de antibióticos, incluindo doses, diluições e intervalos; além das reações adversas.

Outro fator que também impulsiona o processo de resistência relaciona-se com a introdução no mercado farmacêutico de inúmeros antibióticos sem evidência de sucesso superior às demonstradas nos ensaios clínicos. Além disso, a utilização de múltiplos fármacos também pode conferir o desenvolvimento de um potente mecanismo de resistência ou da ação de um conjunto de mecanismos. Ao serem administrados aos pacientes em ambiente hospitalar, esses variados medicamentos de amplo espectro, aumentam o risco de desenvolver infecções por patógenos resistentes, através do processo de seleção, alargamento clonal e possível resistência cruzada a outros antibióticos, levando à dificuldade no tratamento dos pacientes (Powers et al., 2018; Djordjevic et al., 2017).

Uma vez presente nos microrganismos, os genes de resistência aos antibióticos têm comportamento persistente e multifatorial na evolução, sendo disseminados nas próximas gerações bacterianas e acarretando no aumento da complexidade e imprevisibilidade do surgimento de colônias de bactérias resistentes. Pesquisas recentes demonstram que esse processo foi influenciado a partir da introdução de algumas rotas alimentares por meio da utilização de antibióticos na agricultura ou da transmissão zoonótica. Partindo desse pressuposto, a humanidade contribuiu involuntariamente para a seleção de bactérias multirresistentes em escala global, diminuindo a eficácia dos antibióticos, bem como no prolongamento da instalação das doenças nos indivíduos, no aumento do número de internações, resultando em maiores índices de morbidade e mortalidade: um fenômeno que pode tornar-se uma pandemia silenciosa que avança vertiginosamente (Loureiro et al., 2016; Hughes, 2014; Vieira et al., 2017; Camou et al., 2017).

\subsection{Mecanismos de resistência bacteriana}

As bactérias utilizam inúmeros mecanismos de resistência contra a ação de antibióticos. Tais processos podem ser classificados em quatro tipos básicos: a modificação antibiótica; impedimento da ação do antibiótico em seu alvo; alteração do sítio primário de ligação; e a produção de um alvo alternativo, resistente à ação inibitória do antibiótico. Dentre estes, a modificação antibiótica é a mais comum, ocorrendo através de reações enzimáticas: oxirredução ou a transferência horizontal de genes. Nele, a bactéria mantém o mesmo alvo sensível, porém, o fármaco não consegue alcançá-la. Outras bactérias resistentes, por sua vez, atuam protegendo o alvo de ação do antibiótico, através de bombeamento rápido para o meio extracelular ou até mesmo induzindo o bloqueio de entrada do fármaco na célula, impedindo a ação do mesmo. Na alteração do 
sítio primário de ligação, o antibiótico não consegue atuar em seu alvo, devido a uma mudança estrutural desse sítio. Por fim, há cepas capazes de produzir alvos alternativos, resistentes à ação do antibiótico, ou seja, cria-se uma via metabólica que contorne a ação da droga (Hawkey, 1998; Tenover, 2006; Liu et al., 2020).

Conforme a OMS, há uma significativa taxa de resistência nos seguintes microrganismos: K. pneumoniae contra fármacos como carbapenêmicos e cefalosporinas; E. coli contra cefalosporina e fluoroquinolona; Streptococcus pneumoniae contra penicilina; espécies de Shigella contra fluoroquinolonas, Mycobacterium tuberculosis contra fluoroquinolona, isoniazida e rifampicina; Salmonella não-tifóide contra fluoroquinolonas e Neisseria gonorrhoeae contra cefalosporina. Para Souza et al. (2015), no Brasil, além dos microrganismos supracitados, há ainda altas taxas de resistência em Pseudomonas sp. e S. aureus (Tanwar et al., 2014).

\section{Klebsiella spp.}

K. pneumoniae é responsável por infecções hospitalares, comumente relacionadas ao trato urinário em pacientes de unidade de terapia intensiva que fazem uso de cateteres ou que necessitam de aspiração traqueal. Está entre as principais bactérias isoladas em exames laboratoriais. A família desta bactéria tem como principal mecanismo de resistência a produção da enzima betalactamase, que é codificada por plasmídeos e transmitida aos descendentes após os processos de reprodução (Oliveira et al., 2011; Chen et al., 2020).

A carbapenemase pertence à classe A de Amber e ao subgrupo $2 \mathrm{f}$ de Bush. Essa enzima pode conferir resistência aos antimicrobianos conhecidos como betalactâmicos como as cefalosporinas, penicilinas, monobactâmicos e carbapenêmicos. Os principais genes envolvidos nesse processo são blaKPC, blaIMP, blaVIM, blaNdm e blaOxa. Entretanto a literatura reconhece outros tipos de genes da betalactamase mutados que também podem estar ligados à transferência de resistências entre as bactérias do gênero Klebsiella, dentre eles: TEM-1, TEM-2 E SHV-1, que têm mecanismo de hidrolisar ampla variedade de penicilinas e cefalosporina de terceira geração (Tanwar et al., 2014; Oliveira et al., 2011; Seibert et al., 2014).

Embora as enterobactérias resistentes às carbapenemases que produzem o gene blaNdM sejam encontradas em todo o mundo, somente em 2020, houve o primeiro relato no Brasil deste gene em K. aerogenes, realizado por Soares et al. (2021). O isolado apresentou resistência a meropenem e polimixina $b$.

\section{Escherichia coli}

Normalmente encontrada como parte da microbiota normal do intestino grosso do homem e outros animais, E. coli, traz vários benefícios, inclusive, um controle microbiano local. Entretanto, algumas cepas dessa espécie são nocivas e correspondem a agentes etiológicos da enterite e outras doenças extra-intestinais. Essa bactéria utiliza bombas de efluxo presentes nos cromossomos de grande parte das bactérias. A ordem de seu genoma foi definida em 1947, identificando nos cromossomos 4,6 Mpb, quadros de releitura aberta (ORFs), prenunciando a transportação de genes, que chegam em média a 4300 ORFs, dentre eles, vários sujeitos à resistência (Nishino et al., 2006; Anselmo et al. 2015).

\section{Streptococcus pneumoniae}

Para essa bactéria, a recombinação genética é um processo comum, onde um trecho do DNA exógeno é incorporado ao genoma, o que se configura como um excelente mecanismo formador de resistência. O pneumococo, nesse quesito, possui grande vantagem, já que sua taxa de variação genética e recombinação é muito elevada em relação a microrganismos comuns. Estudos apontam que seus genes de resistência podem ser classificados em mef(E) ou mef(A), que atuam na indução da bomba de efluxo, exercendo papel notório na aceleração de saída do fármaco da célula (Chaguza et al., 2015). 


\section{Shigella}

É um dos principais responsáveis pela diarreia em crianças, especialmente em países em desenvolvimento. Segundo a Foodborne Diseases Active Surveillance Network (Foodnet) do Centers for Disease Control and Prevention (CDC), Shigella é a terceira mais prevalente dentre os patógenos de origem alimentar. Em cepas resistentes à ciprofloxacino há substituição de aminoácidos em suas moléculas. Em algumas bactérias desse gênero estão presentes nos genes ipaH, ipaBCD e stx1, mais prevalentes em Shigella dysenteriae do tipo I, resistentes à sulfametoxazol-trimetoprim, rifampicina, ácido nalidíxico, gentamicina, ampicilina, tetraciclina, eritromicina, ciprofloxacina, norfloxacina e estreptomicina (Bastos et al., 2010; Silva et al., 2008).

\section{Mycobacterium tuberculosis}

Não são incomuns os casos de multirresistência neste patógeno, sendo mais comumente resistentes à isoniazida e rifampicina. Em 2008, a OMS orientou a técnica de GenoType MTBDR 1.0®, de amostras pulmonares com baciloscopias positivas, a qual detectou altos índices de resistência à isoniazida, devido às mutações no códon 315 do gene KatG, e baixos índices naqueles, cuja mutação se dá no gene inhaA. Atualmente, já existe uma variação dessa técnica, a qual permite inclusive análise do $M$. tuberculosis, mesmo em baciloscopias negativas (Rueda et al., 2015).

\section{Salmonella spp.}

Salmonella é uma bactéria intestinal causadora de graves intoxicações alimentares. Nos anos 90 sua resistência a antibióticos aumentou drasticamente e desde então tem sido um problema de saúde pública. Estudos recentes indicaram a existência de pelo menos nove efluentes de drogas (mecanismo do qual a bactéria se utiliza para criar resistência) em Salmonella, oito deles sendo também encontrados na bactéria $E$. coli. Relatou-se que a mutação no gene acrR colabora com a superexpressão de acrAB e potencializa a resistência a inúmeras drogas. Através de um teste de susceptibilidade usando disco difusão para 12 antimicrobianos, identificaram o maior nível de resistência para Nitrofurantoína e Ácido Nalidíxico. Além desses, também houveram isolados resistentes à tetraciclina, ampicilina, cefoxitina, ceftazidima, ciprofloxacina e sulfametoxazol (Nishino et al., 2006; Anselmo et al., 2015).

\section{Neisseria gonorrhoeae}

Uma das principais causadoras de gonorreia, uma infecção sexualmente transmissível (IST), configura-se como grande prioridade da saúde pública mundial, não apenas pela grande incidência, - chegou a atingir 78 milhões de casos entre adultos em todo o globo ao final de 2012 - mas também pelos crescentes casos de resistência. Atualmente, há relatos de resistência às sulfonamidas, penicilinas e tetraciclinas. Quanto às sulfonamidas, a resistência gonocócica se dá por meio do aumento da produção do substrato competitivo para a enzima diidropteroato sintetase (DHPS) ou por meio da síntese de uma DHPS mutada que apresenta baixa afinidade para o fármaco. Já no que concerne à penicilina, a resistência ocorreu por meio de mutações cromossômicas cumulativas em genes que atuam na síntese da parede celular (genes penA e ponA1) ou em estruturas que interferem na concentração periplasmática do medicamento (penB, penC e mtrR) (Wi et al., 2017; CostaLourenço et al., 2017).

\section{Pseudomonas spp.}

Classificada como bacilo gram-negativo não fermentador de glicose, está associada a infecções nosocomiais em pacientes imunodeprimidos e em ventilação mecânica. No Brasil, é comum causar infecções de sítios cirúrgicos, queimaduras e até septicemias graves. Dentre os principais mecanismos de resistência há a produção da enzima betalactamase, 
hiperexpressão de sistema de efluxo, alteração da permeabilidade da membrana e síntese de proteína de ligação à penicilina (PBP) com baixa afinidade por betalactâmico, são os mais expressivos. No Brasil, o gene envolvido no desenvolvimento de resistência aos antimicrobianos betalactâmicos é o bla SPM-1 encontrado em Pseudomonas isoladas de Unidades de Terapia Intensiva (UTI) (Santos et al., 2015; Machado et al., 2011).

\section{Staphylococcus aureus}

São bactérias sensíveis a altas temperaturas, desinfetantes e soluções antissépticas, podendo sobreviver em superfícies secas por expressivo período de tempo. S. aureus é responsável por provocar infecções simples a graves, como impetigo e furúnculos até meningite, pericardite, bacteremia e síndrome do choque tóxico, possuindo significativas capacidades de adaptação e resistência a uma grande variedade de antibióticos. Tende a ser fatal para pacientes em longos processos de internação e com debilidade do sistema imunológico (Lima et al., 2018; Aguayo-Reyes et al., 2018).

Sua resistência é caracterizada pela existência de um plasmídeo que codifica a enzima penicilinase, a qual tem como função a inativação, por hidrólise, do anel betalactâmico. Dentre os principais antibióticos que S. aureus é resistente, encontram-se: meticilina, oxacilina e vancomicina, tendo como principais genes codificantes o mecA e vanA. Há ainda uma associação com a evolução da proteína de ligação à penicilina (PBP), sendo conhecidos dois subtipos, PBP2a e PBP2', que estão associadas à resistência a todos os antibióticos betalactâmicos. Os mecanismos de aquisição de resistência são conferidos pela mutação no gene de um cromossomo ou através dos processos de transdução, transformação ou conjugação (Lima et al., 2018; Aguayo-Reyes et al., 2018).

\subsection{Prevalência de bactérias multirresistentes}

Os mecanismos adaptativos supracitados, cada vez mais refinados pelo uso indiscriminado de antibióticos, favorecem certos gêneros para a infecção intra-hospitalar multirresistente. Em um levantamento epidemiológico do perfil microbiano em uma unidade de terapia intensiva com 98 pacientes, as bactérias mais prevalentes foram $P$. aeruginosa, E. coli e $K$. pneumoniae, totalizando quase metade das infecções (Basso et al., 2016; Lima, 2018). Em outro estudo (Debarba et al., 2017), $66 \%$ das amostras de swab retal coletadas no momento da internação cujas bactérias eram multidroga resistentes, revelou $P$. aeruginosa, que também atingiu o topo da lista em um estudo retrospectivo e transversal (Tabela 1).

Em dois outros estudos com métodos semelhantes, K. pneumoniae dominou os percentuais com boa margem, sendo seguida à risca em um dos estudos por Acinetobacter baumannii. Entre crianças e idosos há uma inversão epidemiológica, sendo mais provável observar enterobactérias produtoras de betalactamases de espectro estendido (ESBL), em especial E. coli, e S. aureus meticilina-resistente (MRSA) (Tabela 1) (Bertão et al., 2018; Mota et al., 2018; Ribas, 2016; Abreu et al., 2018).

Muito embora existam vieses pelas variações das populações de acordo com sua etnia, condição socioeconômica, hábitos e estilo de vida, e levando em consideração o papel bem fundamentado dos centros de controle de infecção hospitalar em cada unidade, tais prevalências abrangentes são necessárias para traçar os principais agentes patogênicos nos quais as pesquisas futuras precisam dar enfoque e as estratégias de saúde pública devem se voltar. 
Tabela 1. Principais bactérias multirresistentes de acordo com o tipo de estudo e população.

\begin{tabular}{|c|c|c|c|}
\hline Autor & Tipo de Estudo & $\begin{array}{c}\text { Espaço } \\
\text { Amostral }\end{array}$ & Bactérias Mais Prevalentes \\
\hline \multirow[t]{3}{*}{ Mota et al, 2018.} & \multirow{3}{*}{$\begin{array}{l}\text { Estudo retrospectivo com } \\
\text { pacientes de UTI adulta. }\end{array}$} & \multirow[t]{3}{*}{222} & Klebsiella pneumoniae $(35,5 \%)$. \\
\hline & & & Escherichia coli $(24,1 \%)$. \\
\hline & & & Acinetobacter baumannii $(14,3 \%)$. \\
\hline \multirow[t]{3}{*}{ Basso et al, 2016.} & \multirow{3}{*}{$\begin{array}{l}\text { Estudo retrospectivo } \quad \text { com } \\
\text { pacientes de UTI adulta. }\end{array}$} & \multirow[t]{3}{*}{98} & Pseudomonas aeruginosa $(17,3 \%)$. \\
\hline & & & Escherichia coli $(16,3 \%)$ \\
\hline & & & Klebsiella pneumoniae $(13,2 \%)$. \\
\hline \multirow[t]{3}{*}{ Bertão et al, 2018.} & \multirow{3}{*}{$\begin{array}{l}\text { Estudo } \\
\text { multiespecialidade que incluiu } \\
\text { apenas bactérias produtoras de } \\
\text { betalactamases. }\end{array}$} & \multirow[t]{3}{*}{132} & Klebsiella pneumoniae $(71,2 \%)$. \\
\hline & & & Escherichia coli $(28 \%)$. \\
\hline & & & Proteus mirabilis $(0,8 \%)$. \\
\hline \multirow[t]{3}{*}{ Ribas AC, 2018.} & \multirow{3}{*}{$\begin{array}{l}\text { Estudo observacional e transversal } \\
\text { com pacientes com idade maior ou } \\
\text { igual a } 60 \text { anos internados em UTI } \\
\text { adulta. }\end{array}$} & \multirow[t]{3}{*}{79} & Escherichia coli $(31,7 \%)$. \\
\hline & & & Klebisiella pneumoniae $(12,9 \%)$. \\
\hline & & & $\begin{array}{l}\text { Staphylococcus aureus meticilina- } \\
\text { resistente }(10,5 \%) \text {. }\end{array}$ \\
\hline \multirow[t]{3}{*}{ Debarba et al, 2018.} & \multirow{3}{*}{$\begin{array}{l}\text { Estudo restrospectivo e transversal } \\
\text { com pacientes de UTI adulta. }\end{array}$} & \multirow[t]{3}{*}{62} & Pseudomonas aeruginosa (31\%). \\
\hline & & & Staphylococcus aureus (18\%). \\
\hline & & & Klebsiella pneumoniae (13\%). \\
\hline \multirow[t]{3}{*}{ Lima VS, 2018.} & \multirow{3}{*}{$\begin{array}{l}\text { Estudo retrospectivo e transversal } \\
\text { que incluiu pacientes colonizados } \\
\text { com bactérias multirresistentes à } \\
\text { admissão hospitalar. }\end{array}$} & \multirow[t]{3}{*}{53} & Pseudomonas aeruginosa (66\%). \\
\hline & & & Klebsiella pneumoniae $(16,9 \%)$. \\
\hline & & & Acinetobacter baumannii $(11,3 \%)$. \\
\hline
\end{tabular}

Fonte: Autores.

As consequências do uso irracional de antibióticos intra-hospitalares, não se restringem ao âmbito nosocomial. Um estudo realizado por Zagui et al. (2021), apontou que doses elevadas de antibióticos vindouras de um hospital terciário em São Paulo - SP/Brasil, afetou a composição microbiana de seu esgoto, selecionando bactérias resistentes para amoxicilina, ampicilina, ceftazidima, clindamicina, vancomicina, tendo o fenótipo multirresistente (MDR) atribuído a cerca de $60,7 \%$ das amostras isoladas, apresentando ainda bactérias que compõem a classificação prioritária (crítica/alta) pela Lista de Patógenos Prioritários da OMS: Enterococcus e S. aureus resistentes à vancomicina e Enterobacteriaceae resistentes aos carbapenêmicos, no esgoto hospitalar.

\section{Considerações Finais}

A principal causa de resistência bacteriana continua sendo o uso irresponsável dos antimicrobianos, sendo uma realidade na sociedade atual, seja na medicina, agricultura, criação de animais ou por meio da veiculação hídrica. Diversos estudos sobre os mecanismos bioquímicos de farmacorresistência foram realizados, determinando uma escalada exponencial e potencial dos mesmos. Esse cenário demonstra que ainda há fragilidade e inconsistências na execução dos protocolos de segurança e higiene, realizados por equipes responsáveis pelo cuidado da saúde da população, intra e extra-hospitalares. Todo esse viés é refletido na redução do combate às doenças bacterianas, impacto econômico elevado, resultando em grandes gastos 
hospitalares e aumento da morbidade e mortalidade dos indivíduos. Além disso, mais e maiores estudos sobre o perfil de suscetibilidade e prevalência microbiana são necessários para traçar estratégias de saúde pública voltadas ao controle da farmacorresistência. Assim, são necessárias análises posteriores, e em larga escala, de estratégias educativas populacionais e das equipes multidisciplinares de linha de frente, bem como planejamentos governamentais voltados à saúde pública, evitando os riscos de negligenciar essa situação delicada e perigosa: a multirresistência bacteriana.

\section{Referências}

Abreu, M., Leite, J., Portela, A., Alves, V. \& Almeida, R. (2016). Infeções Por Bactérias Multirresistentes em Idade Pediátrica: Estudo Retrospetivo de Sete Anos de um Hospital de Nível I. Acta Pediatr Port. 47,130-8.

Aguayo-Reyes, A., Quezada-Aguiluz, M., Mella, S., Riedel, G., Opazo-Capurro, A., Bello-Toledo, H., Dominguez, M. \& González-Rocha, G. (2018). Bases moleculares de la resistencia a meticilina en Staphylococcus aureus. Rev Chilena Infectol. 35(1), 7-14.

Anselmo, D. B., Werle, C. H. \& Hoffmann, F. L. (2015). Ocorrência de Escherichia coli e Staphylococcus aureus resistentes a antimicrobianos e parasitos Entamoeba coli e Ascaris lumbricoides em merendas escolares. Rev Inst Adolfo Lutz. 74(4), 399-409.

Basso, M. E., Pulcinelli, R. S. R., Aquino, A.R. C. \& Santos, K. F. (2016). Prevalência de infecções bacterianas em pacientes internados em uma unidade de terapia intensiva (UTI). RBAC. 48(4), 383-8.

Bastos, F. C., \& Loureiro E. C. B. (2010). Caracterização da resistência antimicrobiana de amostras de Shigella spp. isoladas em Belém, Estado do Pará, Brasil (1990-2000). Rev Pan-Amaz Saude,1(4):71-74.

Bertão, M. V., Furtado, I., Machado, A. \& Reis, E. (2018). Estirpes Produtoras de Beta-Lactamases de Espectro Alargado: A Realidade num Hospital Central. Medicina Interna. 25(3), 179-185.

Bush, K. (1989). Characterization of $\beta$-lactamases. Antimicrob Agents Chemother. 33(3), 259-263.

Camou, T., Zunino, P. \& Hortal, M. (2017). Alarma por la resistencia a antimicrobianos: situación actual y desafíos. Rev. Méd. Urug. 33(4), 104-127.

Chaguza, C., Cornick, J. E. \& Everett, D. B. (2015). Mechanisms and impact of genetic recombination in the evolution of Streptococcus pneumoniae. Comput Struct Biotechnol J. 13(2015), 241-247.

Chen, D., Li, H., Zhao, Y., Qiu, Y., Xiao, L., He, H., Zheng, D., Li, X., Huang, L., Yu, X., Xu, N., Hu, X., Chen, Y. \& Chen, F. (2020). Characterization of carbapenem-resistant Klebsiella pneumoniae in a tertiary hospital in Fuzhou, China. Journal of Applied Microbiology. 129(5), $1220-1226$.

Clardy, J., Fischbach, M. \& Currie, C. (2009). The natural history of antibiotics. Curr Biol. 19(11), R437-R441.

Costa-Lourenço, A. P. R., Santos, K. T. B., Moreira, B. M., Fracalanzza, S. E. L. \& Bonelli, R. R. (2017). Antimicrobial resistance in Neisseria gonorrhoeae: history, molecular mechanisms and epidemiological aspects of an emerging global threat. Braz J Microbiol [Internet]. 48(4), 617-628.

Debarba, E., Silvero, K. S. V., Teixeira, J. J. V., Silva, C. M. \& Peder, L. D. (2017). Prevalência microbiana em secreções traqueais de pacientes em unidade de terapia intensiva - Experiência de 4 anos [ahead of print]. Journal of Infection Control. 7(1), 14.

Del Fio, F. S., Mattos Filho, T. R. \& Groppo, F. C (2000). Resistência Bacteriana. Revista Brasileira de Medicina (Rio de Janeiro). 57(10), 1129-1140.

Djordjevic, Z. M., Folic, M. M. \& Jankovic, S. M. (2017). Previous Antibiotic Exposure and Antimicrobial Resistance Patterns of Acinetobacter spp. and Pseudomonas aeruginosa Isolated from Patients with Nosocomial Infections. Balkan Med J. 34(6), 527-33.

Djouadi, L. N., Selama, O., Abderrahmani, A., Bouanane-Darenfed, A., Abdellaziz, L., Amziane, M., Fardeau, M. L. \& Nateche, F (2017). Multiresistant opportunistic pathogenic bacteria isolated from polluted rivers and first detection of nontuberculous mycobacteria in the Algerian aquatic environment. $J$ Water Health. 15(4), 566-579.

Gay, N., Leclaire, A., Laval, M., Miltgen, G., Jego, M., Stephane, R., Jaubert, J., Belmonte, O. \& Cardinale, E (2018). Risk Factors of Extended-Spectrum $\beta$ Lactamase Producing Enterobacteriaceae Occurrence in Farms in Reunion, Madagascar and Mayotte Islands, 2016-2017. Vet Sci. 5(1), 22.

Hawkey, P. M. (1998). The origins and molecular basis of antibiotic resistance. BMJ [Internet]. 317(7159), 657-60.

Hughes, D (2014). Selection and evolution of resistance to antimicrobial drugs. IUBMB Life. 66(8), 521-529.

Kapadia, S. N., Abramson, E. L., Carter, E. J., Loo, A. S., Kaushal, R., Calfee, D. P. \& Simon, M. S (2018). The Expanding Role of Antimicrobial Stewardship Programs in Hospitals in the United States: Lessons Learned from a Multisite Qualitative Study. Jt Comm J Qual Patient Saf. 44(2), 68-74.

Lima, M. F. P., Borges, M. A., Parente, R. S., Victória Júnior, R. C. \& Oliveira, M. E. (2018). Staphylococcus aureus e As Infecções hospitalares Hospitalares - Revisão de Literatura. Revista UNINGÁ Review. 21(1), 32-39.

Lima, V. S. (2018). Avaliação das culturas de vigilância em pacientes sob risco de colonização por bactérias multirresistentes à admissão hospitalar (Monografia). [Aracaju]: Universidade Federal do Sergipe. 51 p. https://ri.ufs.br/handle/riufs/7863

Liu, M., Ma, J., Jia, W. \& Li, W. (2020). Antimicrobial Resistance and Molecular Characterization of Gene Cassettes from Class 1 Integrons in Pseudomonas aeruginosa Strains [ahead of print, 2020 May 14]. Microb Drug Resist. 2020,10.1089/mdr.2019.0406. 10.1089/mdr.2019.0406 
Loureiro, R. J., Roque, F., Rodrigues, A. T., Herdeiro, M. T. \& Ramalheira, E (2016). O uso de antibióticos e as resistências bacterianas: breves notas sobre a sua evolução. Rev. Port. Sau. Pub. 34(1), 77-84.

Machado, G. M., Lago, A., Fuentefria, S. R. R. \& Fuentefria, D. B. (2011). Occurrence and the susceptibility to antimicrobial agents in Pseudomonas aeruginosa and Acinetobacter sp. at a tertiary hospital in southern Brazil. Rev. Soc. Bras. Med. Trop. 44(2), 168-172.

Miquet, G. (2017). Resistencia a los antimicrobianos. Revista de Investigaciones Agropecuarias. $43(1), 3$.

Mota, F. S., Oliveira, H. A. \& Souto, R. C. F. (2018). Perfil e prevalência de resistência aos antimicrobianos de bactérias Gram-negativas isoladas de pacientes de uma unidade de terapia intensiva. RBAC. 50(3), 270-7.

Mota, L., Vilar, F., Dias, L., Nunes, T. \& Moriguti, J. (2010). Uso racional de antimicrobianos. Medicina (Ribeirao Preto Online). 43(2), 164-72.

Nishino, K., Latifi, T. \& Groisman, E. A. (2006). Virulence and drug resistance roles of multidrug efflux systems of Salmonella enterica serovar Typhimurium. Molecular Microbiology. 59(1), 126-141.

Oliveira, C. B. S., Dantas, V. C. R., Motta Neto, R., Azevedo, P. R. M. \& Melo, M. C. N. (2011). Frequência e perfil de resistência de klebsiella spp. em um hospital universitário de Natal/RN durante 10 anos. J. Bras. Patol. Med. Lab. 47(6), 589-594.

Padiyara, P., Inoue, H. \& Sprenger, M. (2018). Global Governance Mechanisms to Address Antimicrobial Resistance. Infect Dis (Auckl). 11, 1-4.

Pons, M. J., Toro, M., Medina, S., Saens, Y. \& Ruiz, J. (2020). Antimicrobial agentes, antibacterial resistance and susteinable health. South Soustenability. $1(1), \mathrm{e} 001$

Powers, J. H., Evans, S. R. \& Kesselheim, A. S. (2018) Studying new antibiotics for multidrug resistant infections: are today's patients paying for unproved future benefits? BMJ. 360, k587.

Ribas, A. C. (2018). Prevalência de infecções em idosos internados em uma unidade de terapia intensiva (Monografia). [Passo Fundo]: Universidade Federal da Fronteira Sul. 67 p. https://rd.uffs.edu.br/handle/prefix/3091

Rueda, J., Realpe, T., Mejia, G., Zapata, E. \& Robledo, J. (2015). GenoType MTBDRplus 1.0® para la detección de resistencia cruzada entre isoniacida y etionamida en aislamientos de Mycobacterium tuberculosis multirresistentes. Biomédica. 35(4), 541-8.

Sabathier, L. L. Estudio de resistência a antibióticos del gênero Pseudomonas em muestras de agua del rio Limay [Dissertação de Mestrado]. [Comahue]: Universidad Nacional del Comahue, 2019. 51 p.

Salam, L. B (2020). Unravelling the antibiotic and heavy metal resistome of a chronically polluted soil. 3 Biotech. 10(238), 23 p.

Santos, I. A. L., Nogueira, J. M. R. \& Mendonça, F. C. R. (2015). Mecanismos de resistência antimicrobiana em Pseudomonas aeruginosa. RBAC. 47(1-2), 512 .

Seibert, G., Hörner, R., Meneghetti, B. H., Righi, R. A., Forno, N. L. F. \& Salla, A. (2014). Infecções Hospitalares por enterobactérias produtoras de Klebsiella pneumoniae carbapenemase em um hospital escola. Einstein (São Paulo). 12, (3), 282-6.

Silva, T., Nogueira, P. A., Magalhães, G. F., Grava, A. F., da Silva, L. H. P. \& Orlandi, P. P. (2008). Characterization of Shigella spp. by antimicrobial resistance and PCR detection of ipa genes in an infantile population from Porto Velho (Western Amazon region), Brazil. Mem Inst Oswaldo Cruz, Rio de Janeiro, 103(7): 731-733.

Soares, C. R. P., Oliveira-Júnior, J. B., \& Firmo, E. F. (2021). Primeiro relato de um gene resistente ao blaNDM em um isolado clínico de Klebsiella aerogenes do Brasil. Revista da Sociedade Brasileira de Medicina Tropical. 54, e02622020.

Souza, E. S., Belei, R. A., Carrilho, C. M. D. M., Matsuo, T., Yamada-ogatta, S. F., Andrade, G., Perugini, M. R. E., Pieri, F. M., Dessunti, E. M. \& Kerbauy, G. (2015). Mortalidade e riscos associados à infecção relacionada à assistência à saúde. Texto Contexto Enferm. 24(1), 220-8.

Souza, M. V., Reis, C. \& Pimenta, F. C. (2005). Revisão sobre aquisição gradual de resistência de Staphylococcus aureus aos antimicrobianos. Revista de Patologia Tropical. 34(1), 27-36.

Tanwar, J., Das, S., Fatima, Z. \& Hameed, S. (2014). Multidrug Resistance: An Emerging Crisis. Interdisciplinary Perspectives On Infectious Diseases. 2014, (541340), 1-7.

Tenover, F. C. (2006). Mechanisms of Antimicrobial Resistance in Bacteria. Am J Med. 119(6), S3-10, S62-70.

Vieira, P. N. \& Vieira, S. L. V. (2017). Uso irracional e resistência a antimicrobianos em hospitais. Arq. Cienc. Saúde UNIPAR. 21(3), 209-212.

Wi, T., Lahra, M. M., Ndowa, F., Bala, M., Dillon, J. R., Ramon-Pardo, P., Eremin, S. R., Bolan, G. \& Unemo, M. (2017). Antimicrobial resistance in Neisseria gonorrhoeae: Global surveillance and a call for international collaborative action. PLoS Med. 14(7), e1002344.

Zagui, G. S., Tonani, K. A. A., Fregonesi, B. M., Machado, G. P., Silva, T. V., Andrade, L. N., Andrade, D., \& Segura-Muñoz, S. I. (2021). Esgoto hospitalar terciário como reservatório de bactérias expressando o fenótipo MDR no Brasil. Jornal Brasileiro de Biologia. 82, e234471. 